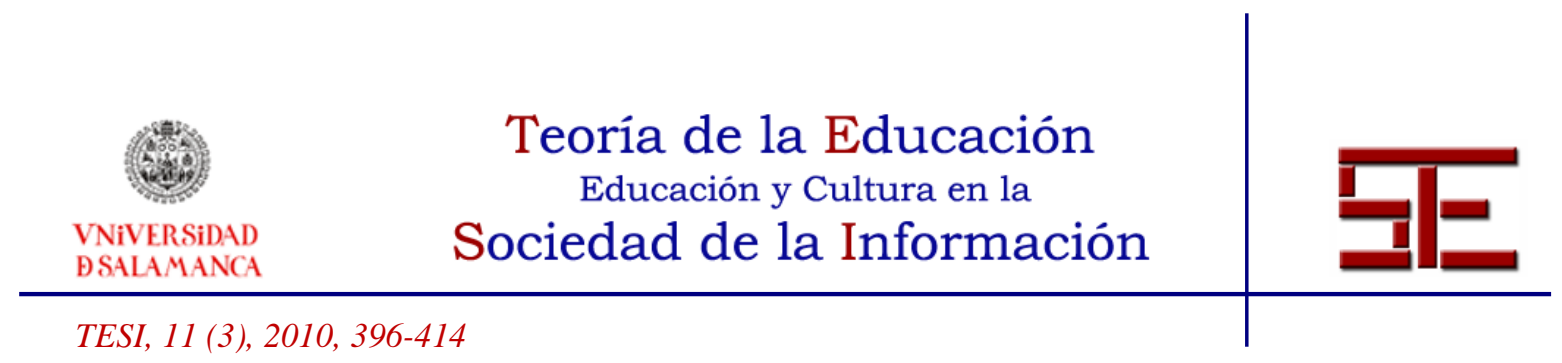

\title{
CATEGORÍAS CONCEPTUALES PARA EL ESTUDIO DEL CONOCIMIENTO ESTRATÉGICO EMPLEADO AL INTERACTUAR CON SIMULACIONES EDUCATIVAS
}

Resumen: En este trabajo se presentan algunas relaciones entre elementos provenientes de referenciales psicológicos a los fines de elaborar un marco referencial que permita interpretar y comprender las acciones que se realizan durante prácticas escolares con simulaciones computacionales que incluya, además de conceptos propios del proceso de aprendizaje de una disciplina particular, conceptos que refieran a las relaciones sociales, tanto interacciones entre personas como los vínculos de las personas con la cultura, las instituciones sociales y la estructura social. Desde un enfoque constructivista social, se propone constituir el objeto de estudio en el sistema persona más herramienta en un contexto situado en el aprendizaje de la ciencia escolar, a fin de obtener categorías para indagar sobre el conocimiento estratégico empleado por los estudiantes al utilizar simulaciones educativas y la influencia de éstas en el aprendizaje de las Ciencias. Consideramos que el estudio del conocimiento estratégico puesto en juego por alumnos en clases de ciencias cuando interactúan con simulaciones computacionales es un problema de la mediación tecnológica de los aprendizajes. Por tal razón, desde la perspectiva socio-histórica se han seleccionado las siguientes categorías: la mediación instrumental, el carácter distribuido de la cognición, la zona de desarrollo próximo y el carácter situado de la cognición.

Palabras clave: simulaciones computacionales educativas; conocimiento estratégico; categorías conceptuales; constructivismo socio-histórico

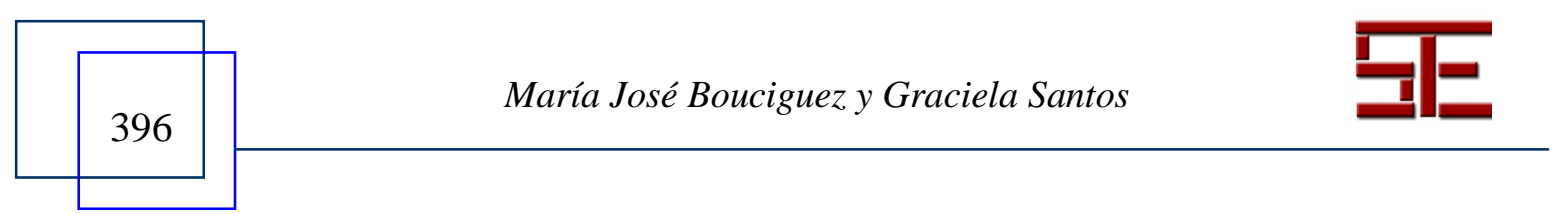




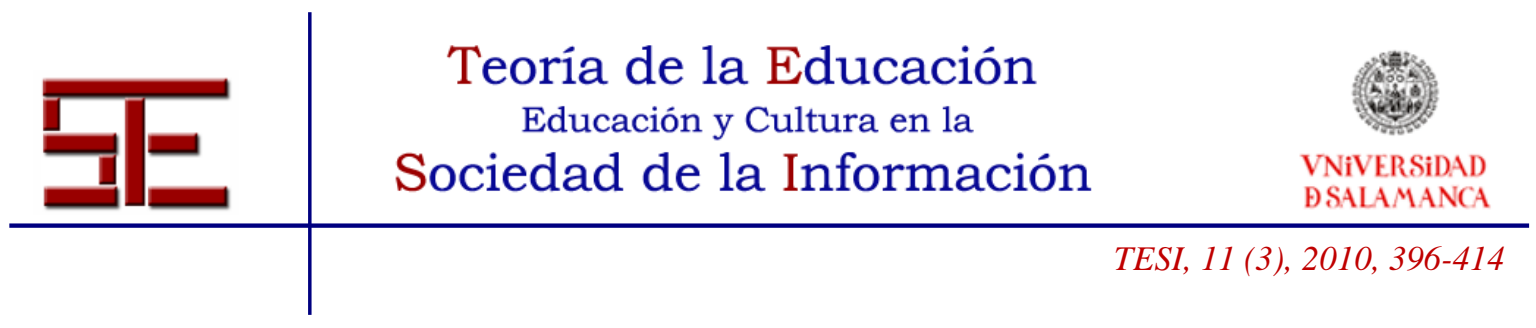

\title{
CONCEPTUAL CATEGORIES FOR THE STUDY OF STRATEGIC KNOWLEDGE USED WHEN INTERACTING WITH EDUCATIONAL SIMULATIONS
}

\begin{abstract}
In this paper, we introduce some relationships between elements coming from psychological referentials with the purpose of developing a referential framework for interpreting and understanding the actions that take place during school practices with computer simulations that include, in addition to concepts of the learning process of a particular discipline, concepts that refer to social relationships, not only interactions among people but also between people with to culture, social institutions and social structure. From a social constructivist approach is proposed to constitute the object of study in the system person + tool in the situated context in the learning of science in the school, in order to obtain categories that allow us investigate the strategic knowledge employed by the students when they use educational simulations and the influence of the latter in science learning. We believe that the study of the strategic knowledge performed by the students in science classes when they interact with computer simulations is an issue of the technological mediation of learning. For that reason, from the socio-historical perspective we have selected the following categories: instrumental mediation, the distributed character of cognition, the zone of proximal development and the situated character of cognition.
\end{abstract}

Keywords: educational computer simulations; strategic knowledge; conceptual categories; socio-historical constructivism.

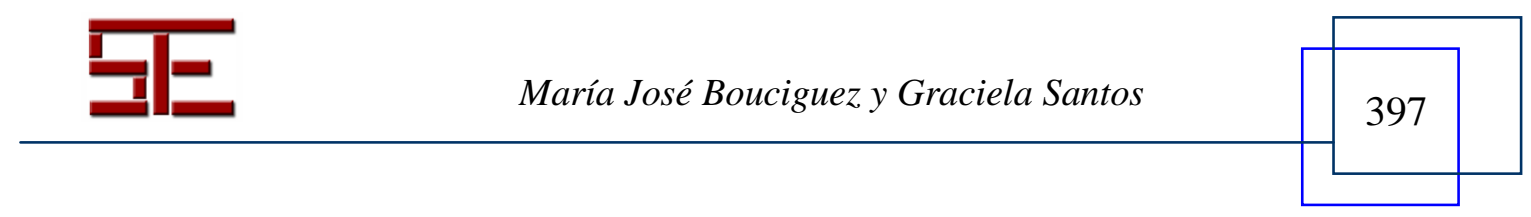




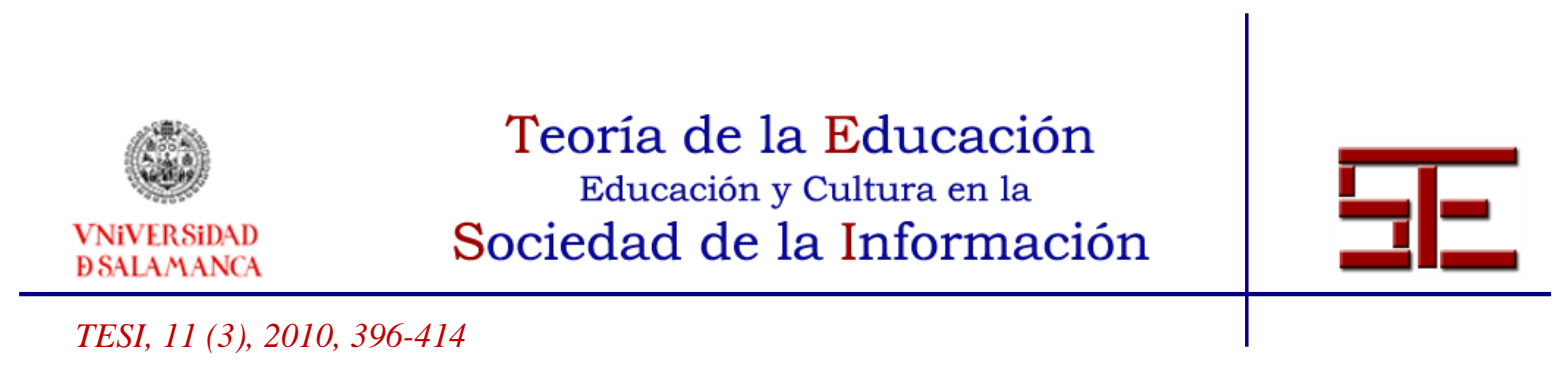

\title{
CATEGORÍAS CONCEPTUALES PARA EL ESTUDIO DEL CONOCIMIENTO ESTRATÉGICO EMPLEADO AL INTERACTUAR CON SIMULACIONES EDUCATIVAS
}

Fecha de recepción: 22/07/2010; fecha de aceptación: 03/09/2010; fecha de publicación: 30/11/2010

\author{
María José Bouciguez \\ mjbouci@exa.unicen.edu.ar \\ Universidad Nacional del Centro de la Provincia de Buenos Aires (UNICEN) \\ Graciela Santos \\ nsantos@exa.unien.edu.ar \\ Universidad Nacional del Centro de la Provincia de Buenos Aires (UNICEN)
}

\section{1.- INTRODUCCIÓN}

En el marco de la educación formal la tecnología digital es pensada e interpretada, en la mayoría de los casos, en términos de aproximaciones que enfatizan las acciones externas del intercambio entre las personas y la tecnología, desestimando las acciones y decisiones de naturaleza interna, estrategias cognitivas con las que se tratan los símbolos, representaciones, ideas, imágenes, conceptos, etc. (Coll y Valls, 1992).

A lo largo de la historia las innovaciones tecnológicas han mostrado que generan prácticas diferenciadas y dinamizan cambios en la estructura social. En la actualidad, las transformaciones sociales están dadas principalmente por las Tecnologías de la Información y Comunicación (TIC).

Las nuevas acciones posibilitadas por las tecnologías trascienden al aparato mismo (como por ejemplo la computadora, teléfono, TV, etc.), se integran y arraigan en las actividades cotidianas de las personas. Las nuevas tecnologías, si bien se desarrollan para ciertos usos y finalidades establecidos, con frecuencia crean posibilidades nuevas e imprevisibles y es imposible prever todos sus efectos de antemano (Burbules y Callister, 2000). Esto permite inferir una relación transaccional en la tecnología y las personas, de manera que al ser utilizadas para transformar el medio éstas transforma a quien las utiliza (Burbules, 2008). A partir de los distintos usos que se hacen de la tecnología en el marco de las instituciones sociales se puede identificar una propiedad de

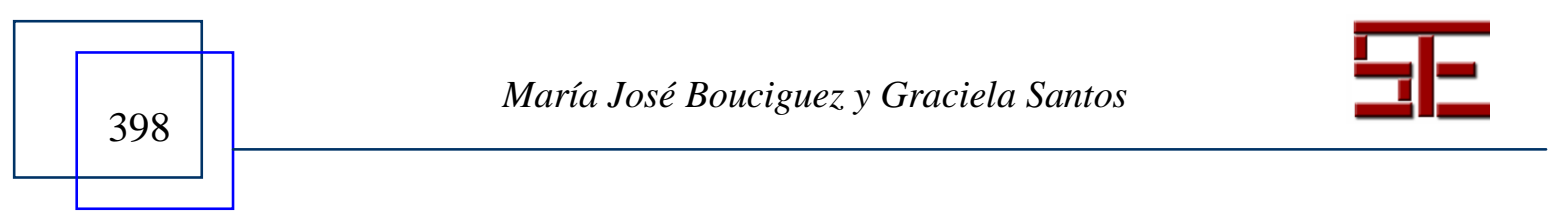




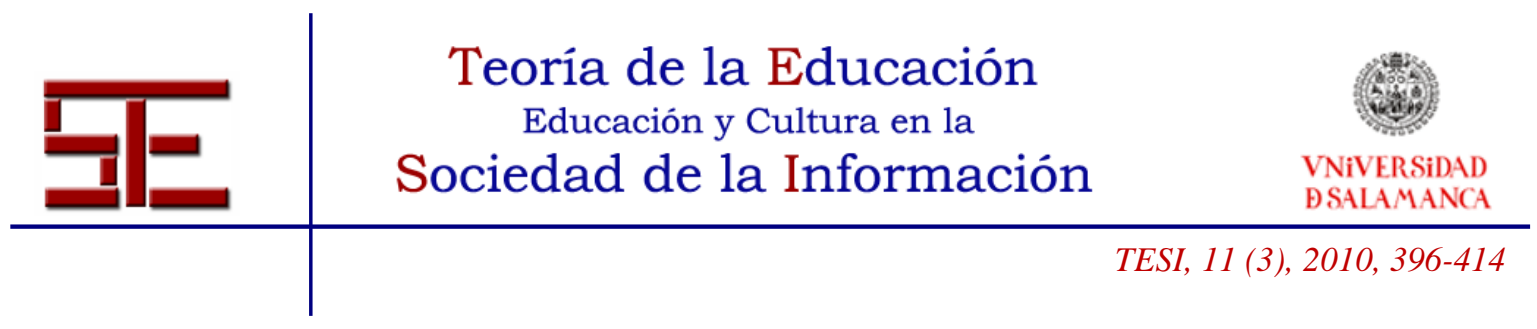

transparencia que favorece e instala, paulatinamente, nuevas prácticas socioculturales (De Pablo Pons, 2009). Así ha ido adquiriendo fuerza el término metáfora para hacer referencia a las distintas formas de expresar las distintas facetas de la relación de los hombres con la tecnología (Rodríguez Illera, 2004).

La tecnología entendida como "instrumentos culturales", físicos o simbólicos, al ser utilizada por los sujetos para la mediación de su acción en el mundo, configura modos de actuar y pensar. Esta perspectiva, más que estudiar modos para mejorar el dominio en el uso de una herramienta, sugiere enfocar hacia los modos de representación simbólicos construidos mentalmente producto de la internalización de las habilidades cognitivas que se desarrollan a consecuencia del uso de las TIC, y que devienen en herramienta de pensamiento (Salomon, 1991). Un residuo cognitivo que se va adquiriendo a través de los continuos intercambios con la tecnología informática en diferentes situaciones y contextos (Salomon; Perkins y Globerson, 1991; Lion, 2006; Escudero, 2009).

Existen estudios que muestran que la mayoría de los jóvenes entre los 17 y los 20 años manejan los códigos digitales desde edades tempranas y dedican mucho tiempo a los videojuegos. Por ejemplo, Begoña Gros y colaboradores $(2002,1)$ sostienen que: “...los videojuegos representan en este momento la entrada de los niños al mundo virtual dotando a éstos de las competencias necesarias para vivir en la sociedad digital... Por este motivo, cuando los niños utilizan el ordenador, usan otros programas informáticos, tienen ya unos conocimientos y destrezas adquiridas fuera del ámbito escolar".

Los chicos se involucran a través de los videojuegos en actividades que requieren respuestas rápidas o "viso motrices" (Gros y Miranda, 2008), o como resolvedor de problemas ambientados en entornos virtuales o simuladores donde se pone en juego el conocimiento estratégico y resuelven (Gros, 2004). Es decir, que en contextos no escolares los estudiantes "resuelven problemas reales (complejos y ambiguos) utilizando estrategias y herramientas cognitivas, y recurriendo a la ayuda de otras personas" (Krajcik; Soloway; Blumenfeld y Marx 2000, 60). Si las prácticas de entretenimiento con videojuegos dejan "residuos cognitivos" (Salomon; Perkins y Globerson, 1991), han de influenciar sobre los nuevos aprendizajes mediados por tecnologías digitales.

Por otro lado, en ambiente escolares, las técnicas de simulación se vienen utilizando desde hace mucho tiempo en diversos campos de la enseñanza y en el campo de la investigación. Hoy en día, las técnicas de simulación constituyen una herramienta imprescindible para la predicción en las ciencias naturales y sociales, y para la tecnología. Con la difusión paulatina de la computadora en las escuelas, se plantea la

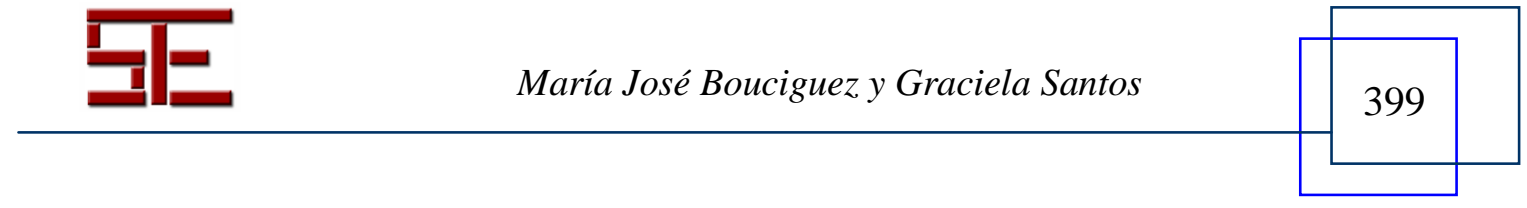




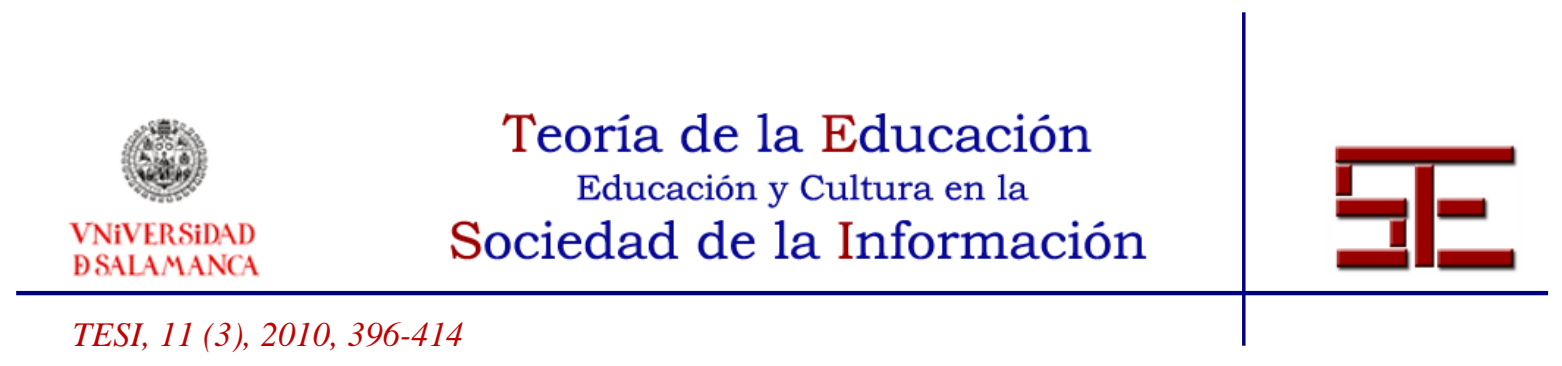

utilización de simulaciones para el aprendizaje de las ciencias, ya que entre otras cosas facilitan la representación dinámica del funcionamiento de un sistema y la visualización de procesos, mostrando la evolución del sistema representado y la interacción entre los componentes o consecuencias de tales interacciones dinámica (Pontes Pedrajas, 2005). Esta posibilidad de manipular y transformar objetos en el espacio de la interfaz, comprometiendo un conjunto diferente de competencias cognitivas (Jonassen y Carr, 2000) en comparación con el uso pedagógico de otros recursos, le otorga a las actividades educativas cierto grado de fortalecimiento pedagógico. En otras palabras, las simulaciones le permitirían al alumno extender y amplificar procesos cognitivos, ayudándolo a resolver problemas complejos y ambiguos, y dar sentido al conocimiento científico (Krajcik et al., 2000); a la vez que se le involucra en el manejo de una amplia gama de códigos científicos y tecnológicos.

Dado que desde las perspectivas constructivistas se le asigna importancia a la manera en que los estudiantes dan sentido a los aprendizajes mediante el análisis y la aplicación de ideas y que el conocimiento es "una construcción situada en un escenario sociocultural específico" (Cubero, 2005, 30), podríamos preguntarnos acerca de los efectos de aprender conocimiento científico "con" simulaciones e indagar sobre la presencia y modos de influencia de experiencias previas con videojuegos. Específicamente, es nuestro interés conocer acerca del conocimiento estratégico que traen y despliegan los estudiantes en la resolución de problemas físicos con simulaciones computacionales educativas.

La finalidad de este artículo es discutir categorías conceptuales que permitan componer un marco de referencia para interpretar y comprender el conocimiento estratégico de los estudiantes con simulaciones computacionales en clases de ciencia desde la perspectiva del constructivismo histórico-cultural.

\section{2.- ENFOQUES ACTUALES DE LAS INVESTIGACIONES EN EDUCACIÓN EN CIENCIA CON TECNOLOGÍA}

En particular, el campo de la enseñanza de la Física es una de las principales áreas donde las posibilidades que ofrece la computadora para el empleo de nuevos métodos de enseñanza requiere aún de una amplia investigación por realizar.

La mayoría de los estudios realizados se concentran en analizar el resultado de los aprendizajes cuando se utilizan simulaciones. Entre estos estudios, Sierra (2004) menciona el realizado por Geban, Askar y Ozkan donde se investigaron los efectos de la

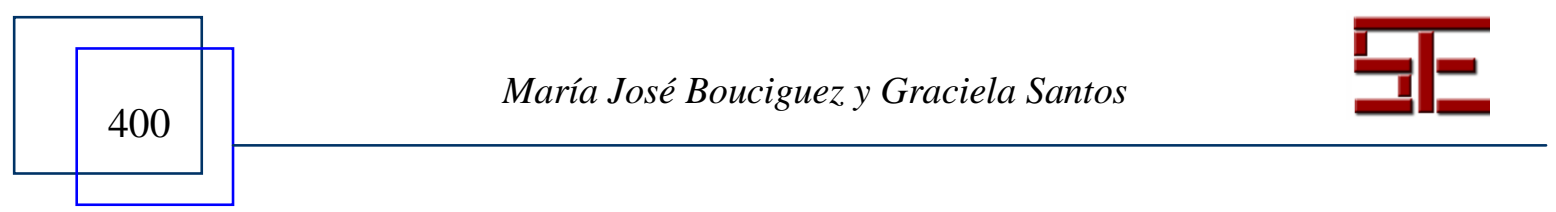




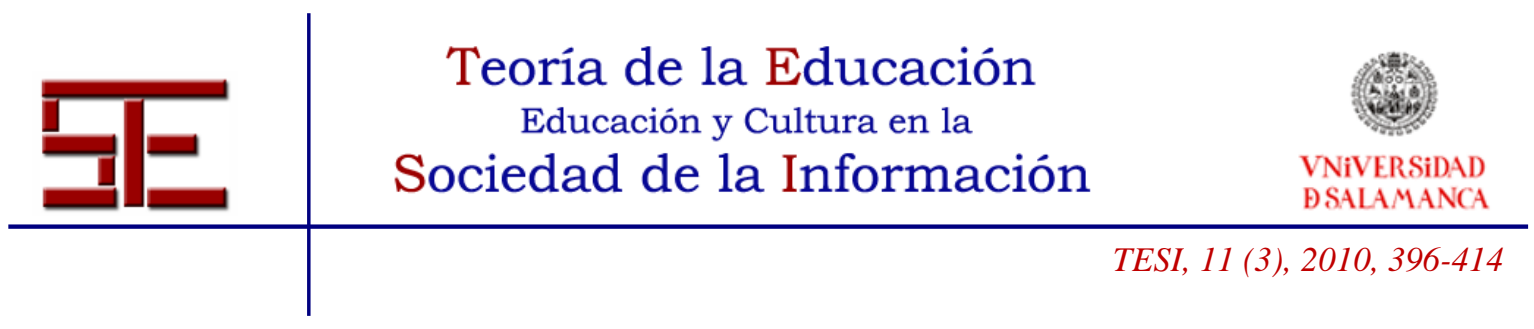

resolución de problemas de química mediante experimentos simulados por ordenador en el aprendizaje de conceptos, destrezas y actitudes de estudiantes de nivel medio. Mediante un grupo experimental y un grupo control pudieron constatar que los alumnos del grupo experimental consiguieron resultados significativamente superiores en el aprendizaje de conceptos, así como de destrezas en los procesos y actitudes científicos.

La función pedagógica de la simulación tiene mucho en común con el rol de la experimentación, cuyo valor es muy valorado en Física. Una simulación permite "experimentar" en condiciones que, muchas veces, resultan difíciles de generar en el laboratorio. Se trata de programas que permiten un alto grado de interacción del alumno con el fenómeno físico representado. Los investigadores Henessy, Twigger, Driver, O’Shea, O’Malley, Byard, Draper, Hartley, Mohamed y Scanlon. (Sierra, 2004, 80) realizaron experiencias con alumnos de entre 12 y 13 años durante 6 semanas usando simuladores para enseñar conceptos relacionados con las fuerzas y la presión, y observaron que los estudiantes que habían usado los simuladores presentaban capacidades de razonamiento superiores.

Dentro de los estudios sobre los efectos de las tecnologías existen estudios experimentales que avanzan en el diseño de interfaces con el objeto de testear sus efectos y sus implicancias en la enseñanza. Un ejemplo es el estudio de Scherly, Roux y Dillengbourg (Lion, 2006, 212) donde se evalúa el uso y la eficiencia de una simulación y un hipertexto para el aprendizaje de virología básica en el primer año de Medicina. Este estudio se dirigió a dos preguntas específicas: (1) ¿cuál de los dos instrumentos era el más eficiente para la adquisición de conocimiento? y (2) ¿existen diferencias en el uso de los hipertextos?

Algunas investigaciones se basan en el desarrollo de simulaciones específicas con la finalidad de estudiar su utilización. Tal es el caso del estudio realizado por Lewis E. L., Stern J. L. y Linn M. C. (Sierra, 2004, 78) donde se investigó el impacto de la simulación en problemas cotidianos sobre la capacidad de extender lo aprendido en clase a los problemas de la vida ordinaria. La hipótesis de la investigación era que los estudiantes cuando investigan activamente problemas referidos a situaciones cotidianas mediante la simulación por ordenador construyen una visión robusta de la termodinámica. También la investigación realizada por Scanlon E. y col. (Sierra, 2004, 81) consiste en el desarrollo de una simulación para evaluar la influencia del diseño en la resolución de un problema abierto de Física. En particular el problema planteado pretendía que el alumno averiguara si es mejor correr o caminar bajo la lluvia al cruzar una calle, con la condición de mojarse lo menos posible.

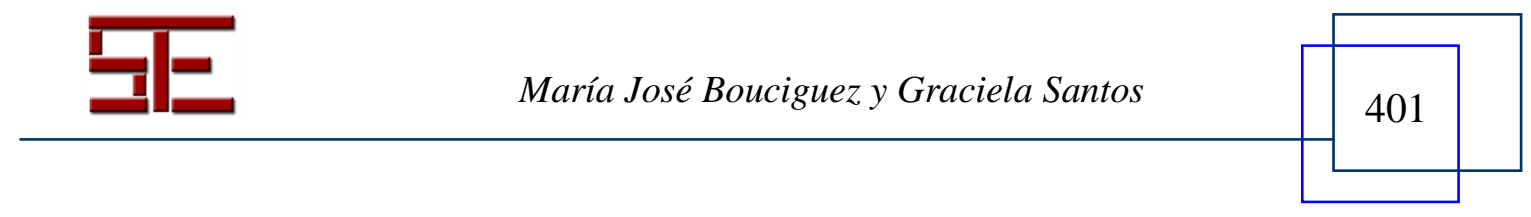




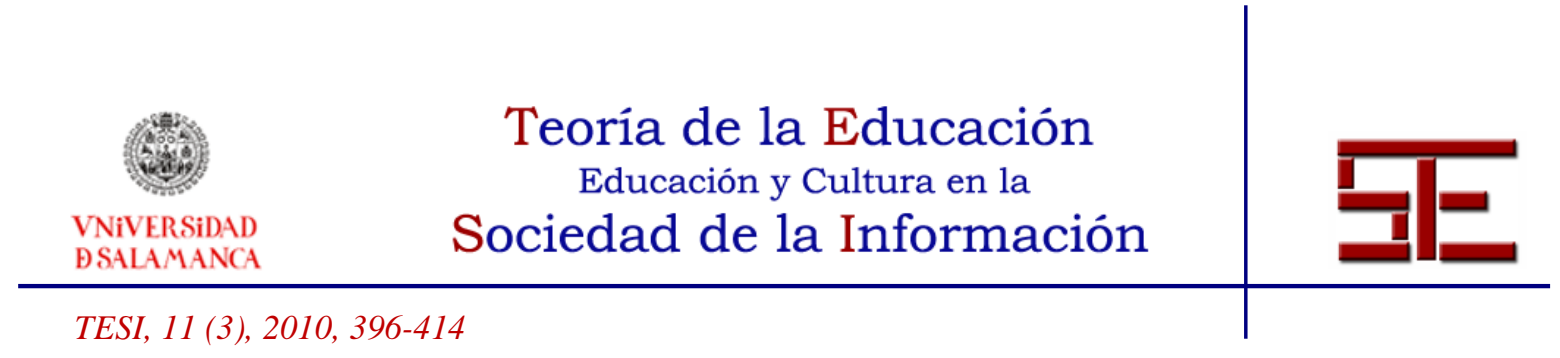

Jimoyiannis y Komis (2001) llevaron a cabo una investigación para estudiar si la utilización de simuladores informáticos desarrollados con Interactive Physics ${ }^{301}$ mejora la comprensión de los estudiantes sobre los conceptos de velocidad y aceleración. Como resultado observaron una evolución en los alumnos del grupo experimental desde unas concepciones alternativas iniciales hacia una comprensión significativa de los conceptos estudiados. Con una idea semejante, la investigación llevada adelante por García Barneto y Bolívar Raya (2005), se plantea como objetivo valorar la eficacia de las simulaciones informáticas en la producción de aprendizajes significativos. Esta investigación se basa en la hipótesis de que "Los alumnos que hacen uso de simulaciones interactivas (applets Java) en un contexto investigativo mediado por ordenador, unen al aumento del interés una mejora en la significatividad del aprendizaje de los conceptos físicos" (García Barneto y Bolívar Raya, 2005, 2). Para comprobarlo realizaron una experiencia en la asignatura de Física (nivel universitario) durante el tratamiento de los temas movimiento armónico simple y ondulatorio; y se llegó a la conclusión de que las simulaciones interactivas mejoran "realmente el aprendizaje de los conceptos físicos, sin embargo, queda margen de progreso $\mathrm{y}$, mientras no se perfeccionen los aspectos educativos de las simulaciones, corremos el riesgo de provocar errores no deseados" (García Barneto y Bolívar Raya, 2005, 4). Un año más tarde, continuando esta línea de investigación se publica un trabajo donde se reafirma la contribución positiva de las simulaciones interactivas en el proceso de enseñanza y aprendizaje, y se enfatiza que la incorporación de las simulaciones informáticas a la enseñanza de la Física debe entenderse como un problema tecnológico y didáctico. Además proporcionan algunas pautas orientativas para el diseño de entornos de aprendizaje basados en simulaciones informáticas. En dicha publicación también se comenta el proyecto de creación de un entorno de aprendizaje constructivista, orientado al tratamiento de los movimientos armónico simple y ondulatorio (García Barneto y Gil Martín, 2006).

En otras disciplinas también se ha estudiado el impacto de las simulaciones sobre los aprendizajes, como, por ejemplo, Lion $(2006,123)$ menciona un estudio experimental realizado con estudiantes de tercer año de la carrera de Arquitectura sobre el diseño con el software Autocad y sin éste. Entre sus hipótesis plantea que "la introducción de software en los procesos de resolución de problemas influye en la secuenciación de los

${ }^{1}$ Interactive Physics ${ }^{\mathrm{TM}}$, programa educativo de Design Simulation Technologies. http://www.designsimulation.com/

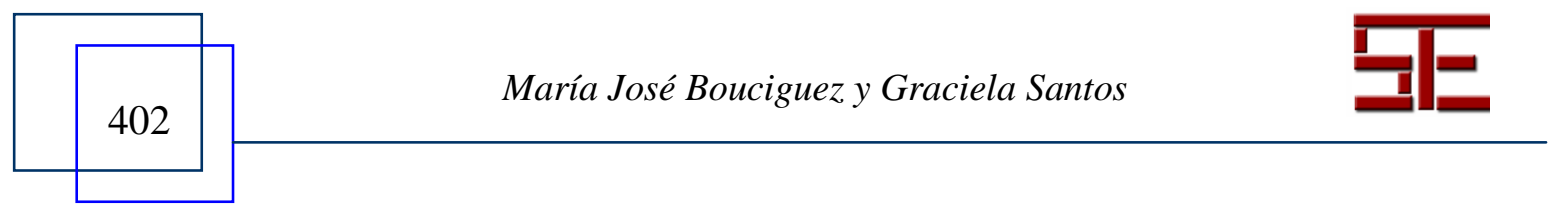




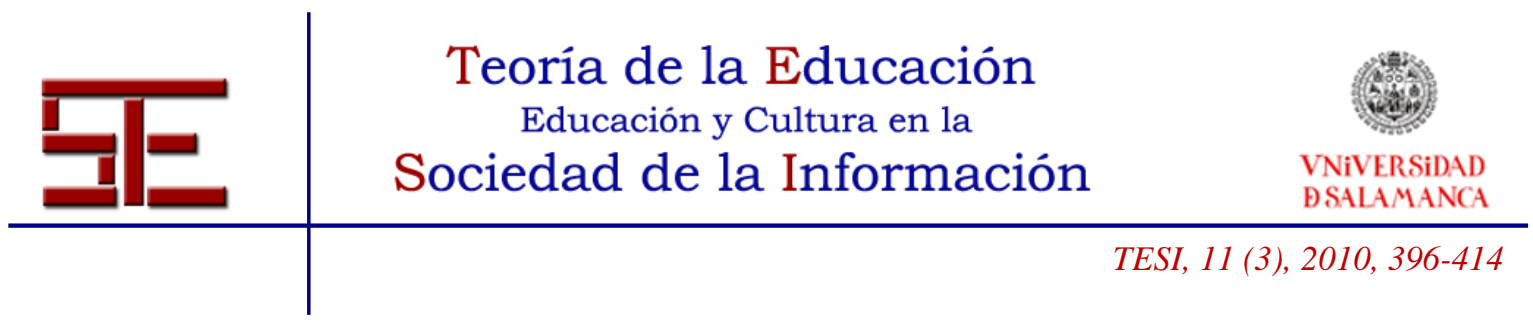

pasos que se consideran y en los criterios que se construyen para dicha resolución" (Lion, 2006, 123), y que "los organizadores gráficos informáticos impactan en la organización de los trabajos y en las huellas perceptivas residuales a la hora de transferir a producciones concretas" (Lion, 2006, 128). Al comparar el grupo experimental y el grupo control se observó que para la tarea de diseño se realiza un análisis diferente del problema y de sus dimensiones, y que podría pensarse que en cierto modo es el programa el que va fijando cuáles son las pautas que deben ponderarse a la hora de diseñar un proyecto. La aplicación informática utilizada con las posibilidades y limitaciones inherentes al desarrollo realizado por los programadores y la particular visión de cómo se realiza la tarea de diseño gráfico condicionan el conjunto de variables a considerar en el análisis del problema. Por otra parte, estaría obstaculizando una revisión crítica en términos de la complejidad de las dimensiones que se involucran en la resolución de un proyecto de este tipo. También se encontraron secuencias diferentes en los procesos de resolución de problemas cuando son mediados tecnológicamente. Lo hallado sobre los organizadores gráficos y espaciales les permitió avanzar en la idea de que los organizadores gráficos pueden ayudar a los estudiantes a encontrar en forma simultánea relaciones entre ideas/proyectos principales y detalles.

La mayoría de las investigaciones antes comentadas se basan en la hipótesis de que la utilización de aplicaciones informáticas mejora o hace más eficiente el aprendizaje de conceptos y procedimientos, y para ello muchas de ellas llevan a cabo estudios de tipo experimental donde dividen la población a estudiar en dos grupos, uno de control y otro experimental.

Sin embargo, consideramos que el estudio de las acciones que se realizan durante las prácticas escolares con simulaciones computacionales requiere la búsqueda de otros planteamientos teóricos que posibiliten incluir, además de conceptos propios del proceso de aprendizaje de una disciplina particular, conceptos que se refieran a las relaciones sociales, tanto interacciones entre personas como las relaciones de las personas con la cultura, las instituciones sociales, la estructura social y la organización política (Chaiklin, 2001). Se propone desde un enfoque interpretativo-crítico componer el objeto de estudio dentro del paradigma sistémico de la persona más herramienta (Pea, 2001) en un contexto situado en lo escolar.

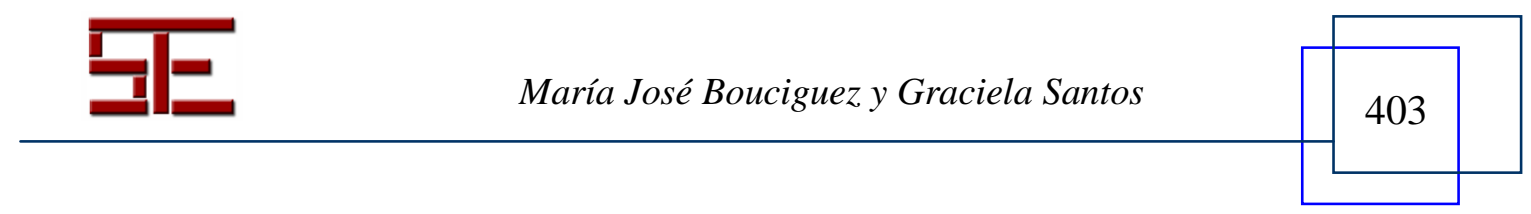




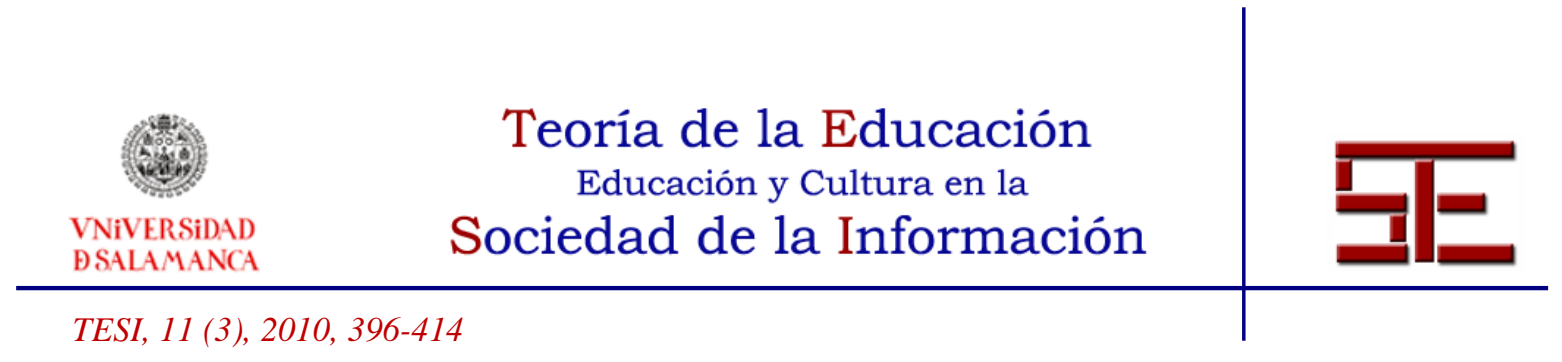

\section{3.- REFERENTES TEÓRICOS PARA INTERPRETAR Y COMPRENDER LO QUE SUCEDE EN CLASES DE CIENCIAS CON SIMULACIONES}

El tema del impacto de las tecnologías en la mente de los sujetos constituye uno de los núcleos más consistentes de la investigación en tecnología y educación (Lion, 2006). Entre los representantes más destacados pueden mencionarse, entre otros, a Pea (2001), Salomon, Perkins y Globerson (1991).

Considerando que el estudio del conocimiento estratégico puesto en juego por alumnos en clases de ciencias cuando interactúan con simulaciones computacionales es un problema de la mediación tecnológica de los aprendizajes, desde la perspectiva sociohistórica se han seleccionado las siguientes categorías: la mediación instrumental, el carácter distribuido de la cognición, la zona de desarrollo próximo y el carácter situado de la cognición, del aprendizaje y de la enseñanza.

La consideración de la herramienta informática como herramienta mediacional es uno de los aspectos más conocidos que surge de considerar un marco de referencia general, como es la teoría socio-histórica, al aprendizaje con computadoras (Rodríguez Illera, 2004). Originalmente, fue Vigotsky (1979) quien postuló el modelo mediacional básico, basado en la idea de que las interacciones del sujeto con los objetos del mundo no son directas sino mediadas por artefactos (herramientas y signos). Luego, Leontiev (1978) desarrolla las ideas acerca de la mediación de los aspectos sociales y culturales en la actividad humana, haciendo hincapié en la interacción de la actividad con la conciencia humana dentro de un contexto relevante, y diferenciando entre la acción individual y la actividad colectiva introducida por la división de tareas. Leontiev (1978) postula que el aprendizaje ocurre en el contexto significativo de la actividad, la que tiene la función de orientar las interacciones del sujeto hacia el objeto, produciendo, por un lado, una transformación exógena (en el objeto, física o mental) y, por otro, una transformación endógena (conocimiento del sujeto).

El enfoque histórico-cultural del aprendizaje sostiene que la mediación instrumental produce un cambio estructural en la cognición humana, donde las herramientas como artefactos culturales orientan la mediación hacia afuera y los símbolos hacia adentro, (Vigotsky, 1979), dos aspectos del mismo fenómeno de mediación bidireccional (Cole y Engeström, 2001).

Dentro de esta perspectiva la computadora es considerada una herramienta cognitiva (Cole y Engeström, 2001; Jonassen; Carr y Yueh, 1998; Jonassen, 1999), un instrumento único de mediación entre las actividades de enseñanza y la asimilación cognitiva (Rodríguez Illera, 2004). Cuando un estudiante aprende a través de una actividad

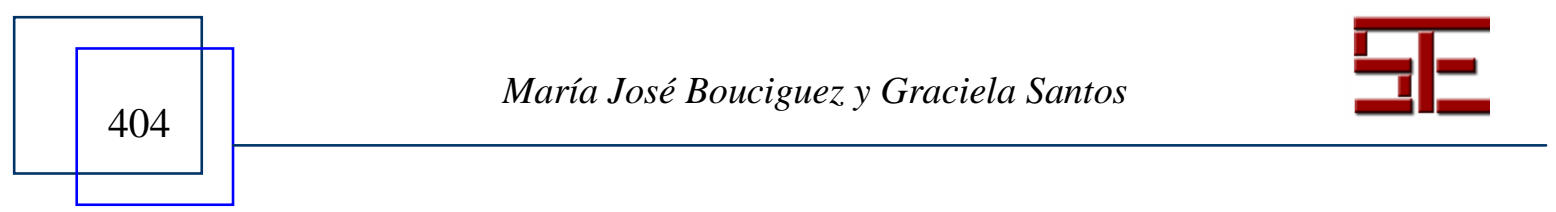




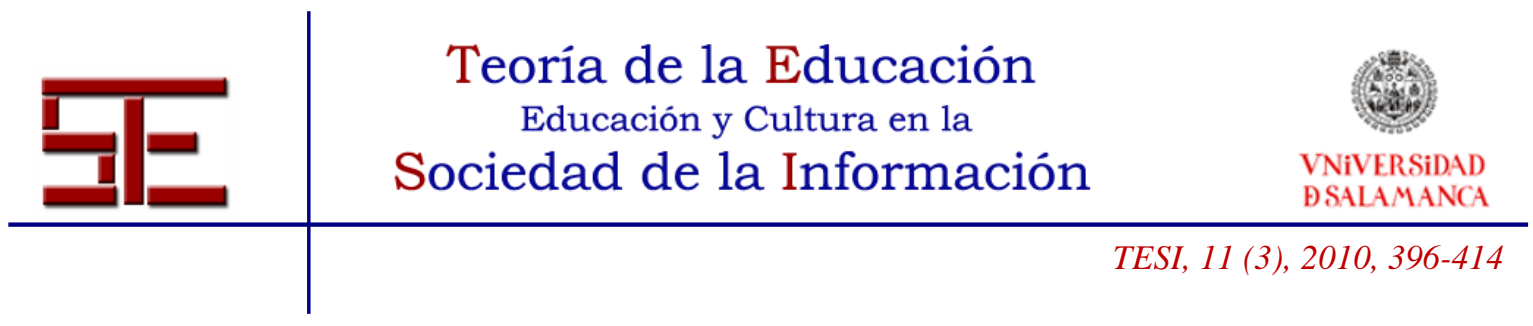

mediada por una aplicación informática adquiere conocimiento de la disciplina que estudia, pero también desarrolla habilidades cognitivas que sólo pueden adquirirse interactuando con "la computadora". Coll y Martí (2001) señalan que las siguientes características de la computadora tendrían efectos en los procesos cognitivos: el formalismo (previsión y la planificación de las acciones) ayuda al desarrollo de autoconciencia y la autorregulación. La interactividad potencia el protagonismo del estudiante, permite la adaptación de la enseñanza a distintos ritmos de aprendizaje y favorece la motivación y la autoestima. El dinamismo ayuda a interactuar con realidades virtuales que simulan situaciones reales, favoreciendo la exploración y la experimentación. La multimedialidad permite diferentes representaciones que se integran y complementan. La hipermedialidad facilita relaciones flexibles y múltiples entre la información. La conectividad abre nuevas posibilidades para el trabajo grupal y colaborativo.

De manera más general se puede entender que al interactuar "con otros o con artefactos culturales" se pone en juego un conjunto de cogniciones distribuidas, cultivando a la vez las competencias del individuo (Salomon, 2001). Siguiendo estas nociones, las simulaciones pueden pensarse como artefactos culturales que posibilitan intercambios entre la cognición y los objetos simbólicos que representan el conocimiento científico.

La idea de la inteligencia (el conocimiento, la cognición) distribuida como sostiene Roy Pea (2001) más que una teoría de la mente nos sirve en nuestro estudio como "marco heurístico para suscitar y formular preguntas teóricas y empíricas" (Pea, 2001) acerca del conocimiento estratégico del estudiante cuando participa en actividades mediadas por herramientas informáticas como las simulaciones.

Cuando un estudiante, como parte de un grupo, emplea una simulación informática para la resolución de un problema acerca de un fenómeno científico, el entorno social y artificial no sólo son la fuente de estímulo y de guía, sino que en realidad son vehículos del pensamiento.

La noción de cogniciones distribuidas nos permite tener en cuenta que, al resolver problemas en contacto con el entorno social y tecnológico, el alumno piensa en asociación con otros, y con la ayuda de herramientas y medios que se les proporcionan. Este sistema que abarca tanto a la persona como el entorno es la unidad de análisis que incluye, a la vez, el pensamiento y el aprendizaje.

Salomon (2001) sostiene que las cogniciones distribuidas y las cogniciones de los individuos deben concebirse en una relación de influencia y de desarrollo mutuos. Por ello es que concluye que, en cuanto a metas de la educación en el dominio cognitivo, las

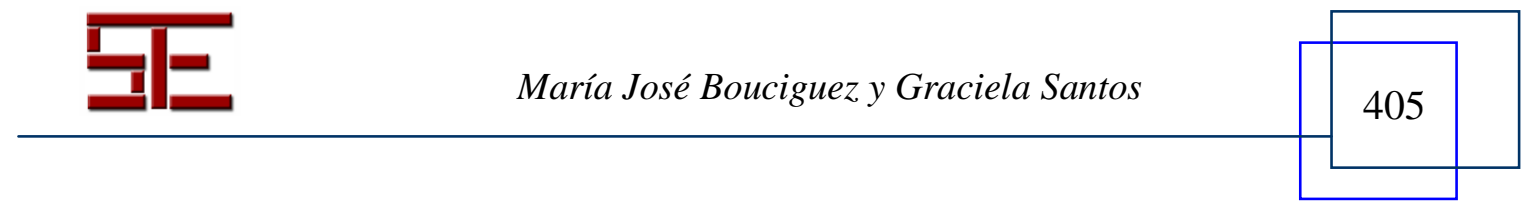




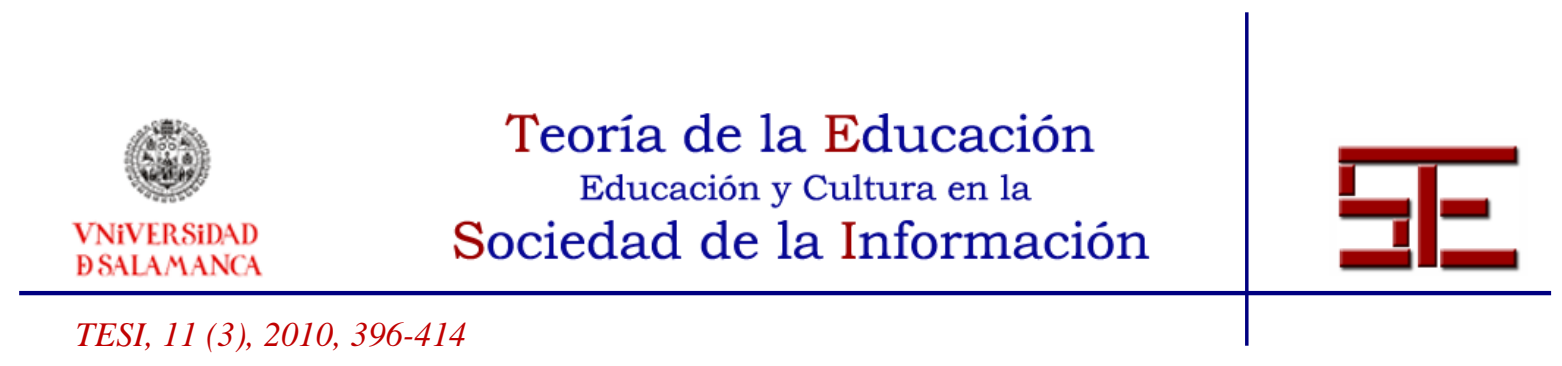

situaciones de cogniciones distribuidas no deben tenerse en cuenta solamente como fines en sí, sino como medios para mejorar el dominio de las competencias "solistas"2.

Los enfoques situados de la cognición, del aprendizaje y de la enseñanza consideran que la actividad mental está inevitablemente anclada en la situación o contexto específico en la que trascurre; una situación dentro de la cual razonamos, pensamos, hablamos, recordamos, imaginamos, etc., influenciados por sus componentes.

Una de las principales tesis de la "cognición situada" considera que el conocimiento no consiste en un "equipamiento de la mente" estático sino que está situado en la actividad (Brown; Ash; Rutherford; Nakagawa y Campione, 2001). Para Lave (2001, 21), "el conocimiento y el aprendizaje se encuentran distribuidos a lo largo de la compleja estructura de actuación de las personas en diversos ambientes. No se los puede individualizar en la cabeza de las personas ni en las tareas asignadas ni en las herramientas externas ni en el medio, sino que reside en las relaciones entre ellos".

"Los modos de conocer están íntimamente vinculados con los artefactos culturales de las situaciones, los cuales incluyen a las personas y las herramientas" (Brown et al., 2001). Cuando en las clases de Ciencias los alumnos trabajan en pequeños grupos con simulaciones computacionales para resolver un problema acerca de un fenómeno, se posibilita su implicación progresiva en actividades auténticas del dominio de la Física, contribuyendo de esta manera al aprendizaje como proceso de enculturación (Díaz Barriga, 2003).

La idea de cognición situada (Brown; Collins y Duguid, 1989) considera que el conocimiento es un producto de la actividad, el contexto y la cultura en que se usa, y que está situado en ellos. Por eso, la comprensión de la práctica educativa como contexto situado hace que sea necesario estudiar la actividad de las personas cuando actúan en contextos determinados, es decir, estudiar lo que dicen y hacen profesores y alumnos en clase mientras se resuelve un problema acerca de unos contenidos de aprendizaje en asociación con simulaciones computacionales.

La metáfora de un aula que sostiene muchas zonas superpuestas de desarrollo próximo y promueve el crecimiento a través de la apropiación mutua y la negociación del significado es la ventana teórica a través de la cual vemos el sistema de la actividad del aula y las prácticas comunitarias que surgen en ella (Brown et al., 2001).

${ }^{2}$ Solista o persona solista en el sentido de"mente en soledad", sin interactuar con herramientas culturales.

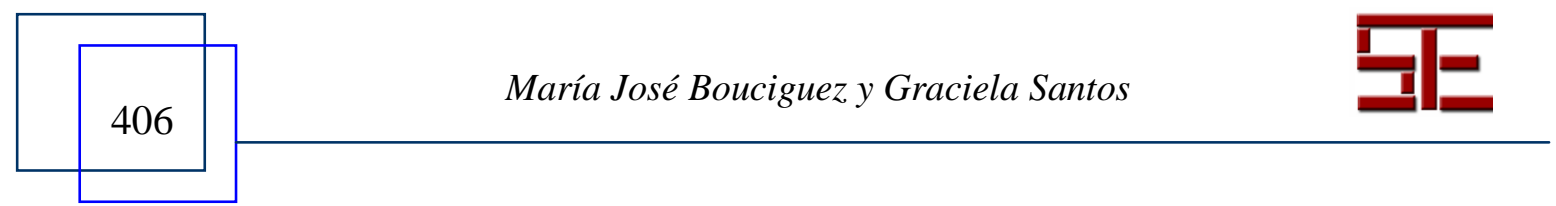




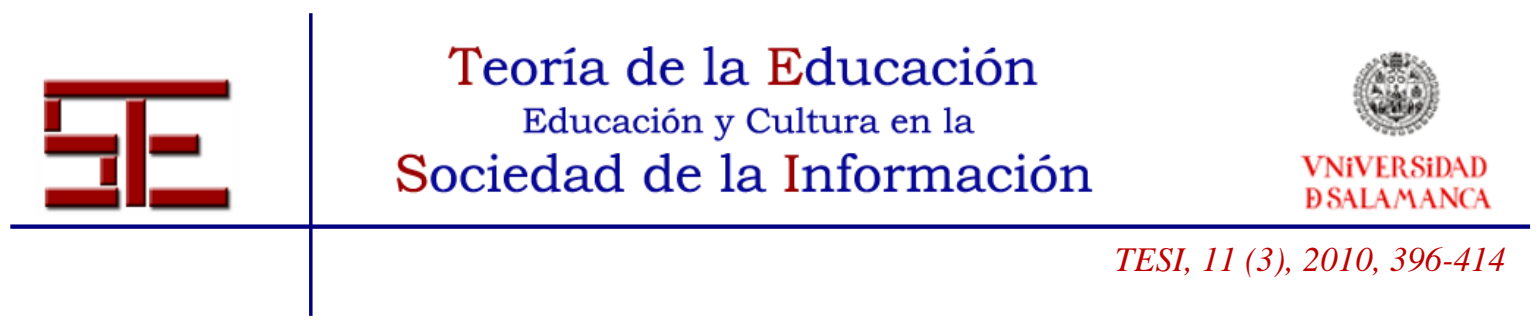

A través de estas Zonas de Desarrollo Próximo (ZDP) los participantes pueden desplazarse por diferentes rutas y a diferentes velocidades.

Una zona de desarrollo próximo es la región de actividad que los alumnos pueden recorrer con ayuda proveniente de un contexto de apoyo, que incluye a personas, con diferentes grados de conocimiento especializado, pero no se limita a ellas (Vigotsky, 1979), sino que puede abarcar también artefactos culturales como puede ser por ejemplo un contexto informático destinado a apoyar un aprendizaje intencional.

La expresión "apropiación mutua" remite a la naturaleza bidireccional en que se produce: "los alumnos de todas las edades, y de todos los niveles de especialización y de interés, siembran el entorno de ideas y de conocimientos de los que diferentes alumnos se apropian en proporción distinta, de acuerdo a sus necesidades y con el estado actual de las zonas de desarrollo próximo en las que se encuentran" (Brown et al., 2001).

Tradicionalmente desde el campo de la tecnología educativa el aprendizaje ha sido pensado en una relación casi diádica con la tecnología, como una especie de efecto de la misma. Pero las diferentes aproximaciones a la tecnología se convierten en grandes metáforas que nos indican cómo pensar esas relaciones entre las personas y las máquinas. Las relaciones entre la tecnología informática y el aprendizaje han estado dominadas por una metáfora instrumental y, en gran medida, ése ha sido uno de los problemas incluso en la manera de pensar los aprendizajes. Cada metáfora expresa una realidad, o una faceta de la compleja realidad que es la relación de los hombres con la tecnología. Pensar la tecnología como texto nos permite analizar la tecnología según un modelo de pensamiento que detecta disposiciones y las "lee" como significativas (Rodríguez Illera, 2004).

En la medida en que haya una mediación cultural en la que exista una interacción tanto con otros agentes sociales como con otras herramientas culturales el ser humano puede aprender o desarrollarse y llegar a funciones de nivel superior. No son solamente las personas sino también las herramientas sociales las que pueden aportar una ayuda en la "fase inter" de la zona de desarrollo próximo. La teoría sociocultural de Vigotsky considera el origen social de los procesos mentales humanos y el papel del lenguaje y de la cultura como mediadores necesarios en la construcción y en la interpretación de los significados. La propuesta vigotskiana destaca también que el conocimiento se construye porque hay una mediación semiótica. Es decir, porque quien ayuda en un momento determinado a otra persona, quien co-construye con esa persona, puede hacerlo porque cuenta con un código que le permite las tres acciones que los lenguajes posibilitan: representarse el mundo, comunicarse con otros y regular la conducta del

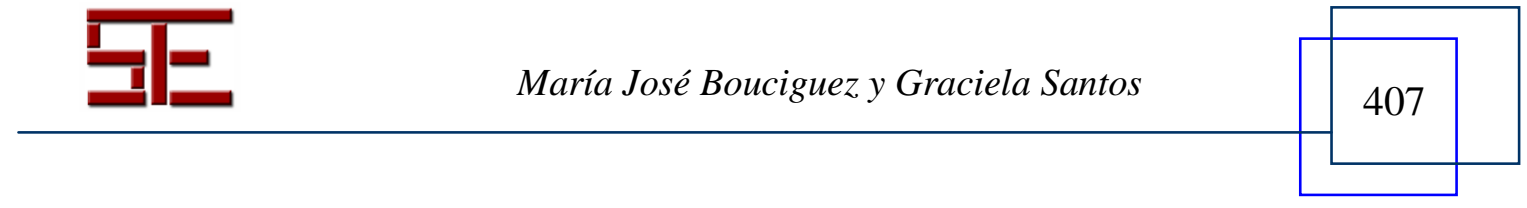




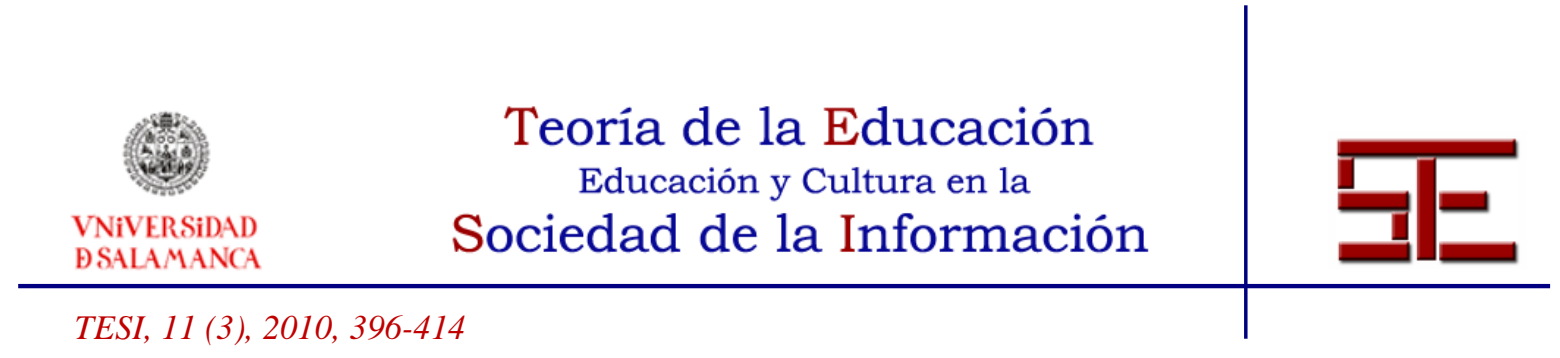

otro. La co-construcción del conocimiento potencia el desarrollo y, por otro lado, esa co-construcción se produce porque hay situaciones de mediación semiótica (Cubero, 2005) y es influida por las características específicas de los códigos utilizados.

\section{4.- CONOCIMIENTO ESTRATÉGIGO EMPLEADO AL INTERACTUAR CON SIMULACIONES COMPUTACIONALES EDUCATIVAS}

Las categorías conceptuales antes mencionadas establecen un marco referencial de dos dimensiones de estudio, una dirigida a los aspectos individuales de la cognición y otra a los aspectos sociales, con el propósito de dar cuenta de la relación entre los residuos cognitivos, la influencia de las tecnologías de la información y la comunicación (Coll y Monereo, 2008) y la enseñanza que se propone en relación con la educación en general, y con la Enseñanza de las Ciencias y la investigación sobre el conocimiento estratégico puesto en juego por los estudiantes al utilizar simulaciones educativas en particular.

En los estudios sobre los efectos que se producen en el intercambio con las tecnologías se sostiene, casi de manera unívoca, que no puede haber un solo mecanismo que dé cuenta de éstos sino que depende de la naturaleza de la tecnología, de las clases de efectos que potencialmente pueda tener, de las circunstancias sociales y psicológicas en las cuales esa tecnología se encuentra y del marco cognitivo individual (Pea, 2001; Salomon, 2001; Salomon; Perkins y Globerson, 1992). Esto se enraíza en una relación de influencia y desarrollo mutuo que existe entre las cogniciones individuales y distribuidas (Salomon, 2001).

Desde las teorías constructivistas, se argumenta la existencia de habilidades de carácter general con cierta independencia del conocimiento disciplinar que posibilitan la planificación de acciones mentales, la supervisión de la comprensión, la evaluación del proceso seguido y de los resultados. Desde este enfoque se habla de la existencia de principiantes "estratégicos". Ante la resolución de problemas académicos se requiere saber qué procedimientos realizar y qué otros conocimientos activar, así como cuándo y por qué. De esta manera, la comprensión de una disciplina no sólo conlleva conocimiento a nivel del contenido, hechos y procedimientos, sino lo que podría llamarse "conocimiento de orden superior" (Perkins y Simmons, 1988), o "conocimiento estratégico" (Monereo, 1997). Este tipo de conocimiento pone énfasis en el proceso de toma de decisiones consciente e intencional sobre que conocimientos (conceptuales, procedimentales y actitudinales) utilizar para alcanzar determinados objetivos, como por ejemplo estrategias de resolución de problemas, estilos de

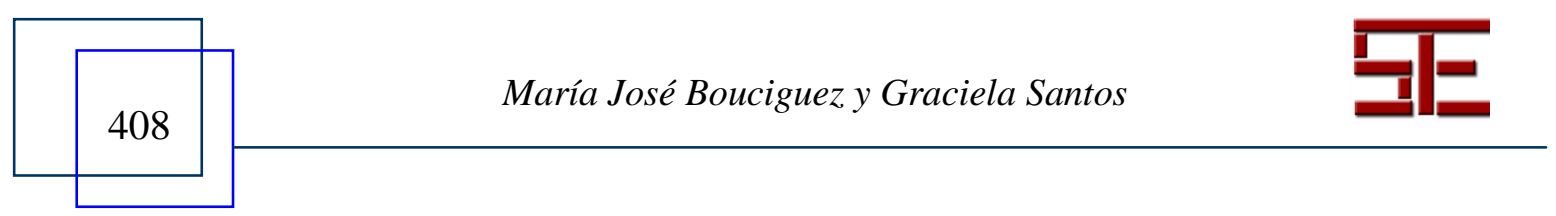




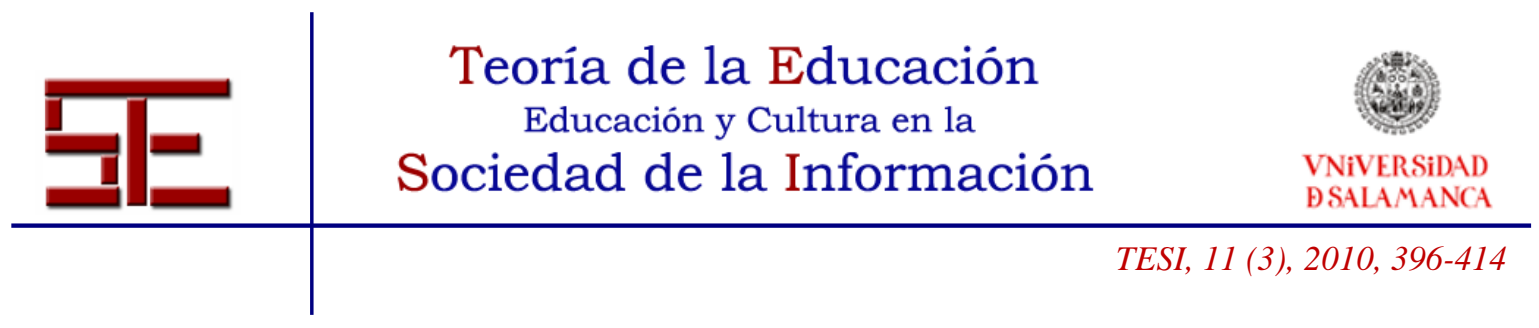

justificación, explicación y características investigativas del dominio.

Cuando el alumno en clases de Ciencias se enfrenta a simulaciones computacionales se conforma una situación de cognición distribuida. Entendiendo por ello que la cognición humana puede concebirse como distribuida más allá del ámbito del propio organismo, y ello en distintos sentidos: abarcando a otras personas, apoyándose en medios simbólicos y aprovechándose del entorno y de los artefactos. Según Perkins (2001, 128), "el entorno, los recursos físicos y sociales inmediatos fuera de la persona, participa en la cognición, no sólo como fuente de entrada de información y como receptor de productos finales, sino como vehículo de pensamiento".

Las investigaciones muestran que los alumnos al interactuar juegos que consisten en simulaciones adquieren determinadas estrategias y habilidades (Gros, 2004). Se podría pensar que, también, las simulaciones en clases de Ciencias permitirían formar puentes entre los conocimientos previos de los estudiantes y la adquisición de nuevos conocimientos, desarrollando conocimiento estratégico para resolver problemas de ciencias. De esta manera, las simulaciones estarían siendo consideradas un "andamio" en la "Zona de Desarrollo Próximo" (ZDP) que ayuda al alumno, con la colaboración del docente y pares, a regular el propio aprendizaje y favorece la apropiación progresiva de conocimientos y estrategias.

En particular nuestro interés se orienta al estudio del conocimiento estratégico que ponen en juego los estudiantes cuando trabajan en asociación intelectual con simulaciones computacionales de fenómenos físicos y la naturaleza de dicho conocimiento en relación a experiencias previas con simuladores en otros contextos. Se lo puede inscribir en el campo de la Tecnología Educativa. Entendiendo como Tecnología Educativa al “...espacio intelectual pedagógico cuyo objeto de estudio son los medios y las tecnologías de la Información y la Comunicación en cuanto formas de representación, difusión y acceso al conocimiento y a la cultura en los distintos contextos educativos: escolaridad, educación no formal, educación informal, educación a distancia y educación superior" (Area Moreira, 2009).

Respecto al tema de los procesos cognitivos en el aprendizaje de las ciencias mediado por tecnología, C. Escudero $(2009,278)$ propone:

...seguir indagando acerca de algunos de los efectos cognitivos de enseñar y aprender con la tecnología; así como comprender mejor cómo el uso de determinadas aplicaciones mejora (o posibilita) nuevos tipos de acciones. Además de contribuir a fundamentar la construcción de una actual concepción de la resolución de problemas escolares en ciencias y su investigación a partir de nuevos marcos teóricos, principalmente psicológicos y sus implicancias pedagógicas y éticas. Respetando el escenario y el movimiento natural de las aulas, se parte del conocimiento de la

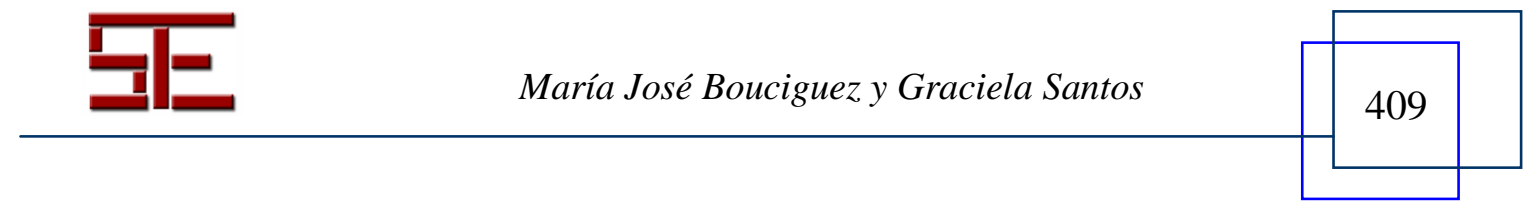




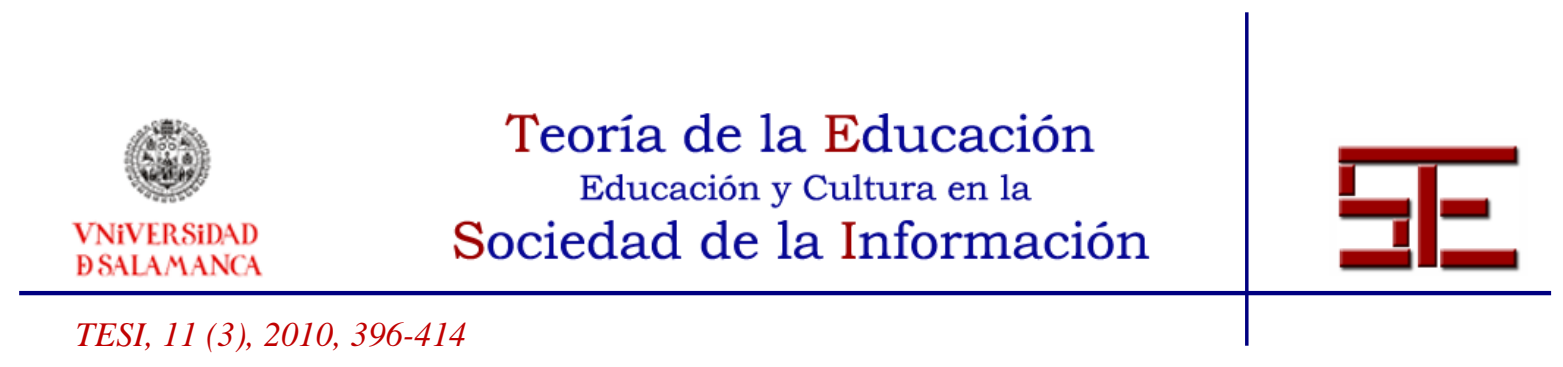

persona y sus capacidades y nos dirigimos hacia el conocimiento de la persona-cuando-utiliza-esa herramienta (computadora).

Adhiriendo a esta idea nos planteamos a continuación algunas cuestiones que nos permitan orientar el estudio sobre el conocimiento estratégico en las interacciones con simulaciones:

¿Cuáles son las estrategias que los alumnos emplean al utilizar simulaciones computacionales para la tarea de resolución de un problema asociado a un fenómeno físico? ¿Cuál es la naturaleza de dichas estrategias? ¿es posible identificar, y en tal caso cual es, la relación entre el conocimiento estratégico desplegado por un alumno y su conocimiento tecnológico previo? ¿es posible caracterizar de alguna manera las estrategias cognitivas empleadas? ¿es posible identificar estrategias de resolución de problemas características del campo de la Física?

Los usos cotidianos de las tecnologías marcan la necesidad de pensar en contextos interpretativos que los doten de sentido y significados. De ahí que los interrogantes antes enunciados sean sumamente complejos, puesto que el proceso interpretativo de los datos debe dar cuenta de un conocimiento enraizado en la cultura y no sólo en las paredes de las aulas.

Buscando dar respuesta a estos interrogantes se plantea como objetivo general: estudiar el conocimiento estratégico que ponen en juego los estudiantes cuando trabajan en asociación intelectual con una simulación computacional para la resolución de un problema acerca de un fenómeno físico.

Específicamente se intenta:

- Caracterizar el conocimiento tecnológico previo de los alumnos principalmente en relación a sus prácticas extraescolares con videojuegos o entornos de simulación.

- Identificar y caracterizar el "conocimiento estratégico" que despliegan durante la resolución de problemas físicos con simulaciones computacionales.

- Analizar las variaciones en los modos de utilización de las simulaciones en términos de conocimiento estratégico.

- Identificar la relación entre el conocimiento estratégico utilizado en simulaciones y la experiencia tecnológica previa.

- Identificar cambios en las estrategias usadas en simulaciones cuando los ambientes poseen elementos componentes similares a los videojuegos.

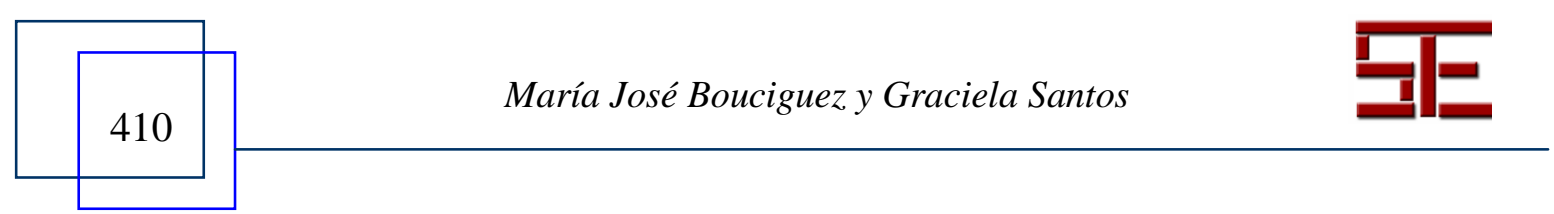




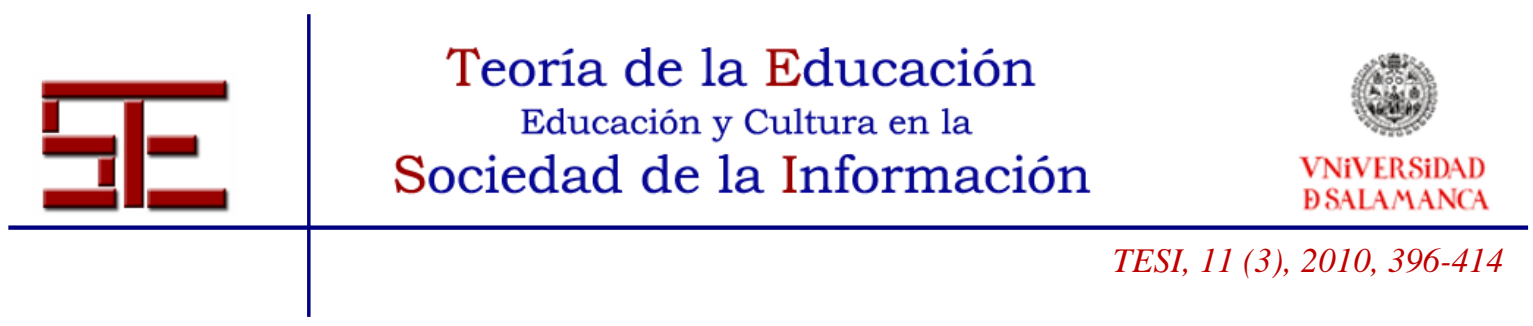

A modo de síntesis, en este artículo se presentan los elementos elegidos, provenientes de referenciales psicológicos, que permiten indagar, interpretar y comprender las prácticas escolares cuando los alumnos utilizan simulaciones computacionales, y orientan el recorte de la misma para que incluya aquellas relaciones que hacen que el fenómeno que deseamos estudiar, la puesta en juego por parte de los alumnos de conocimiento estratégico, se manifieste de ese modo y no de otro, es decir, reconstruir la integridad de las relaciones que le dan existencia, captando el fenómeno en su complejidad pero de modo inteligible. Este recorte de la realidad desembocará en un enunciado problemático lo suficientemente rico como para captar las múltiples relaciones entre niveles de la realidad que podrían estar dando lugar a la ocurrencia del fenómeno. De esta manera los conceptos teóricos seleccionados -mediación instrumental, el carácter distribuido de la cognición, la zona de desarrollo próximo y el carácter situado de la cognición- no se usan en su función explicativa sino como función de articulación y apertura a lo indeterminado.

\section{5.- REFERENCIAS}

Área Moreira, M. (2009). Introducción a la Tecnología Educativa. Manual electrónico. Extraído el 4 abril, 2009 de http://webpages.ull.es/users/manarea/ebookte.pdf.

Brown, A. L., Ash, D., Rutherford, M., Nakagawa, A. G. y Campione, J. (2001). Conocimiento especializado distribuido en el aula. En G. Salomon (comp.), Cogniciones distribuidas. Consideraciones psicológicas y educativas (pp. 242290). Buenos Aires: Amorrortu.

Brown, J. S., Collins, A. y Duguid, P. (1989). Situated cognition and the culture of learning. Educational Researcher, 18, 32-42.

Burbules, N. C. (2008). Riesgos y promesas de las TIC en la educación. ¿Qué hemos aprendido en estos últimos diez años? En C. Magadán y V. Kelly (comps.), Las TIC: del aula a la agenda política. Ponencias del Seminario internacional Cómo las TIC transforman las escuelas (pp. 31-40). UNICEF ARGENTINA, IIPEUNESCO, Sede Regional Buenos Aires.

Burbules, N y Callister, T. (2000). Educación: Riesgos y promesas de las nuevas tecnologías de la Información. Buenos Aires: Editorial Granica.

Chaiklin, S. (2001). Comprensión de la práctica científico-social. En S. Chaiklin y J. Lave (comps.), Estudiar las prácticas. Perspectivas sobre actividad y contexto (pp. 403-427). Buenos Aires: Amorrortu editores.

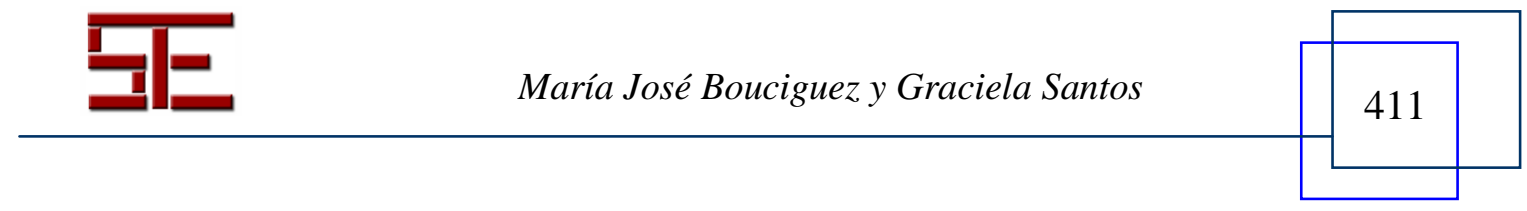




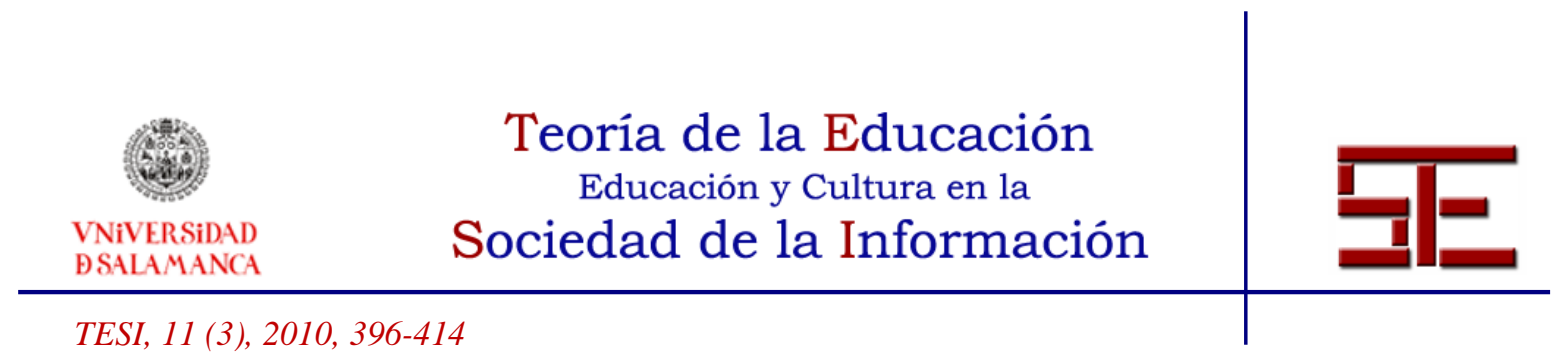

Cole, M. y Engeströn, Y. (2001). Enfoque histórico-cultural de la cognición distribuida. En G. Salomon (comp.), Cogniciones distribuidas. Consideraciones psicológicas y educativas (pp. 23-74). Buenos Aires: Amorrortu.

Coll, C. y Martí, E. (2001). La educación escolar ante las nuevas tecnologías de la información y de la comunicación. En C. Coll, J. Palacios y A. Marchesi (comps.), Desarrollo Psicológico y Educación. 2. Psicología de la Educación Escolar (pp. 623-651). Madrid: Alianza.

Coll, C. y Monereo, C. (2008). Educación y aprendizaje en el siglo XXI: nuevas herramientas, nuevos escenarios, nuevas finalidades. En C. Coll y C. Monereo (eds.), Psicología de la educación virtual (pp. 19-53). Madrid: Ediciones Morata.

Coll, C y Valls, E. (1992). El aprendizaje y la enseñanza de los procedimientos. En C. Coll, J. I. Pozo, B. Sarabia y E. Valls (eds.), Los contenidos de la Reforma. Enseñanza y aprendizaje de conceptos, procedimientos y actitudes (pp. 81-132). Buenos Aires: Santillana (cuarta edición, 1996).

Cubero, Rosario (2005). Perspectivas constructivistas. La Intersección entre significado, la interacción y el discurso. Barcelona: Ed. GRAÓ.

Díaz Barriga, F. (2003). Cognición situada y estrategias para el aprendizaje significativo. Revista Electrónica de Investigación Educativa, 5 (2), 1-13.

Escudero, C. (2009). Una mirada alternativa acerca del residuo cognitivo cuando se introducen nuevas tecnologías. El caso de la resolución de problemas en ciencias. Revista Electrónica Teoría de la Educación: Educación y Cultura en la Sociedad de la Información. 10 (1), 272-292.

García Barneto, A. y Bolivar Raya, J. P. (2005). Uso de simulaciones informáticas en la enseñanza de la física: movimientos armónicos simples y ondulatorio. Revista Electrónica de Enseñanza de las Ciencias. Número extra.

García Barneto, A. y Gil Martín, M. R. (2006). Entornos constructivistas de aprendizaje basados en simulaciones informáticas. Revista Electrónica de Enseñanza de las Ciencias, 5 (2), 304-322.

Gros, B. (2002). Videojuegos y alfabetización digital. Publicado originalmente en la Revista Enredando.com. Extraído 10 de junio, 2009, de http://www.diegolevis.com.ar/secciones/infoteca.html

- (2004). Pantallas, juegos y educación. La alfabetización digital en la escuela. Bilbao: Editorial Descleé de Brouwer S.A.

Gros, B. y Miranda, J. (2008). Con el dedo en la pantalla: El uso de un videojuego de estrategia en la mediación de aprendizajes curriculares. Revista Electrónica

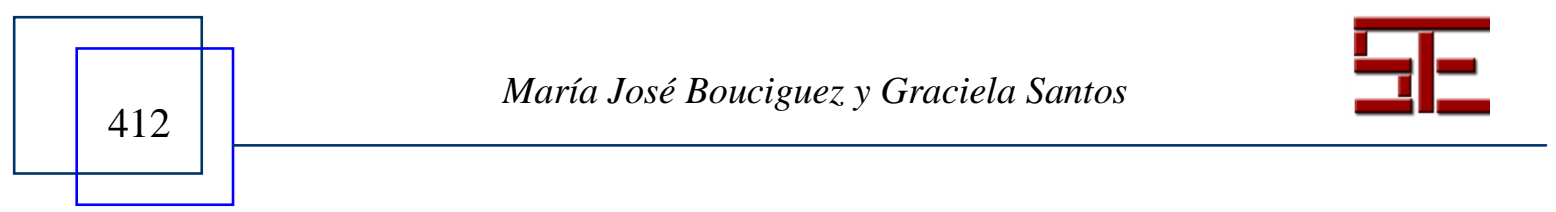




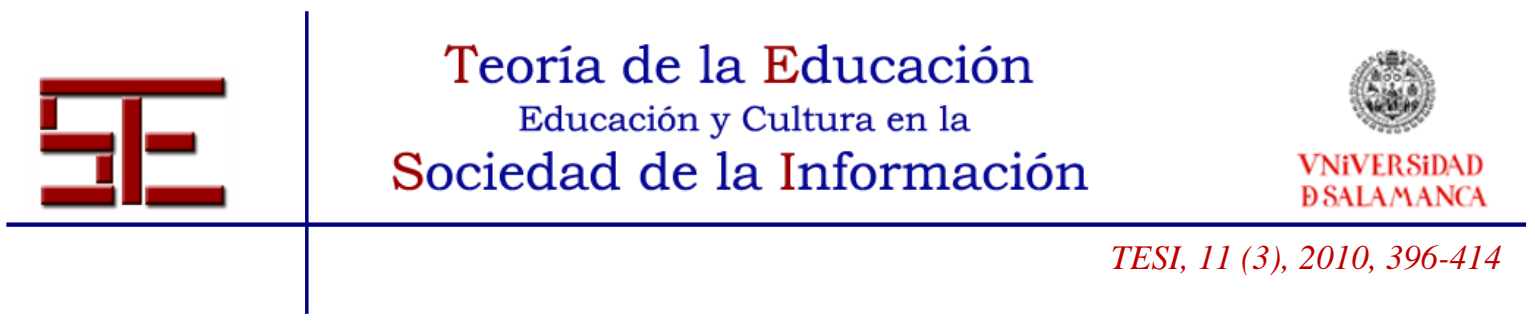

Teoría de la Educación. Educación y Cultura en la Sociedad de la Información, 9 (3), 108-129.

Jimoyiannis, A. y Komis, V. (2001). Computer simulations in physics teaching and learning: a case study on students understanding of trajectory motion. Computers \& Education, 36 (2), 183-204.

Jonassen, D. (1999). Designing consructivist learning environments. En, C. Reigeluth (Ed.) Instructional design theories and models: A new paradigm of instructional theory (pp. 215-239). New Jersey: Lawrence Erlbaum Associates.

Jonassen, D. y Carr, C. (2000). Mindtools: Affording Multiple Knowledge Representations for Learning. En S. P. Lajoie (ed.), Computer as cognitive tools. Mahwah, NJ: Lawrence Erlbaum Associates.

Jonassen, D. H.; Carr, C. \& Yueh, H. (1998). Computers as Mindtools for engaging Learners in Critical Thinking. TechTrends, 43 (2), 24-32.

Krajcik, J.; Soloway, E.; Blumenfeld, P. \& Marx, R. (2000). Un andamiaje de herramientas tecnológicas para promover la enseñanza y el aprendizaje de Ciencias. En C. Dede (comp.), Aprendiendo con tecnologías (pp. 60-77). Buenos Aires: Paidós.

Lave, J. (2001). La práctica del aprendizaje. En S. Chaiklin y J. Lave (comps.), Estudiar las prácticas. Perspectivas sobre actividad y contexto (pp. 15-45). Buenos Aires: Amorrortu editores.

Leontiev, A. N. (1978). Activity, Consciousness and personality. Englewood Cliffs, N. J.: Prentice Hall.

Lion, C. (2006). Imaginar con tecnologías. Buenos Aires: La Crujía Ediciones.

Monereo, C. (1997, noviembre). "Les Demoiselles" de Picasso. Cambio cognitivo y conocimiento estratégico. Ponencia presentada en el III Seminario sobre constructivismo y Educación, Sevilla, España.

Pea, R. (2001). Prácticas de inteligencia distribuida y diseños para la educación. En G. Salomon (comp.), Cogniciones distribuidas. Consideraciones psicológicas y educativas (pp. 75-125). Buenos Aires: Amorrortu.

Perkins, D.N. (2001). La persona-más. Una visión distribuida del pensamiento y el aprendizaje. En G. Salomon (Comp.), Cogniciones distribuidas. Consideraciones psicológicas y educativas (pp. 126-152). Buenos Aires: Amorrortu.

Perkins, D. N. y Simmons, R. (1988). Patterns of misunderstanding: An integrated model for sciencie, math, and programming. Review of Educational Research, $58,303-26$.

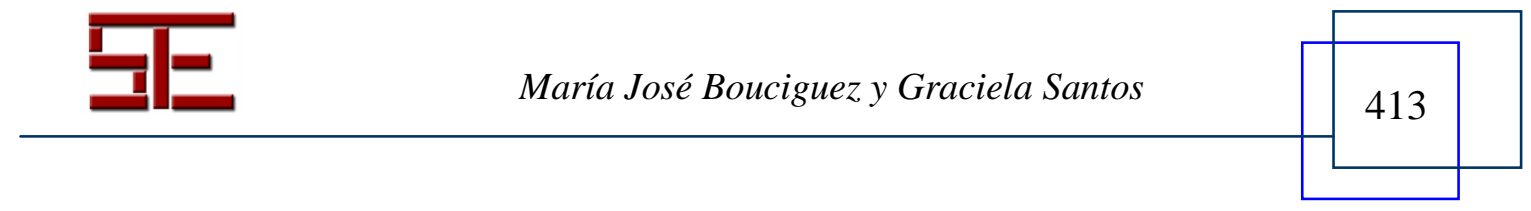




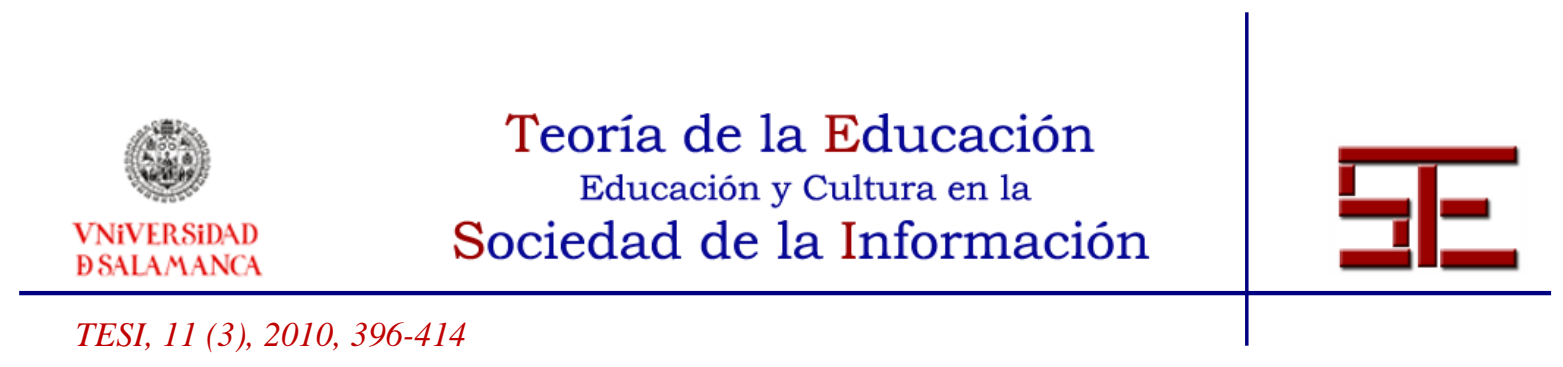

de Pablo Pons, J. (2009). Introducción general. En J. de Pablo Pons (coord.), Tecnología educativa. La formación del profesorado en la era de Internet (pp. 27-42). Málaga-España: Ediciones Aljibe.

Pontes Pedrajas, A. (2005). Aplicaciones de las tecnologías de la información y de la comunicación en la educación científica. Primera parte: funciones y recursos. Revista Eureka sobre Enseñanza y Divulgación de las Ciencias, 2 (1), 2-18.

Rodríguez Illera, J. L. (2004). El aprendizaje virtual: Enseñar y aprender en la era digital. Rosario, Argentina: Ediciones HomoSapiens.

Salomon, G. (2001). No hay distribución sin la cognición de los individuos. Un enfoque interactivo dinámico. En G. Salomon (comp.), Cogniciones distribuidas. Consideraciones psicológicas y educativas (pp. 153-184). Buenos Aires: Amorrortu.

- (1991). Las diversas influencias de la tecnología en el desarrollo de la mente. En L. Tolchinsky Landsmann (Ed.), Culture, Schoolong and Psychological Development. Norwood: Ablex.

Salomon, G; Perkins, D.N. y Globerson, T. (1992). Coparticipando en el conocimiento: la ampliación de la inteligencia humana con las tecnologías inteligentes. Comunicación, Lenguaje y Educación, 13, 6-20

Salomon, G., Perkins, D. N. y Globerson, T. (1991). Partners in Cognition: Extending Human Intelligence with Intelligent Technologies. Educational Researcher, 20 (3), 2-9.

Sierra, J. L. (2004). Estudio de la influencia de un entorno de simulación por ordenador en el aprendizaje por investigación de la Física en Bachillerato. Tesis para optar el título de doctor. Universidad de Granada.

Vigotsky, L. (1979). El desarrollo de los procesos psicológicos superiores. Barcelona: Critica.

Para citar el presente artículo puede utilizar la siguiente referencia:

Bouciguez, M. J. y Santos, G. (2010). Categorias conceptuales para el estudio del conocimiento estrategico empleado al interactuar con simulaciones educativas, en Orejudo González, J.P. (Coord.) Perspectiva educativa y cultural de "juego de rol". Revista Teoría de la Educación: Educación y Cultura en la Sociedad de la Información. Vol. 11, nº 3. Universidad de Salamanca, pp. 396-414 [Fecha de consulta: dd/mm/aaaa]. http://campus.usal.es/ revistas_trabajo/index.php/revistatesi/article/view/7470/7486

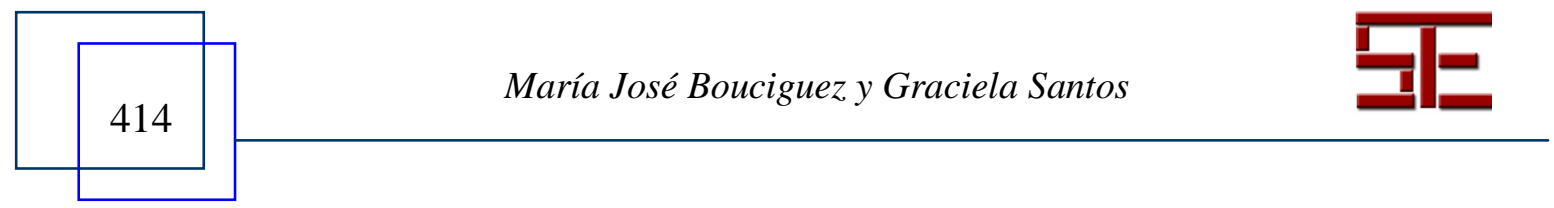

